\title{
Dam Inflow Prediction by using Artificial Neural Network Reservoir Computing
}

\author{
B. Pradeepakumari, Kota Srinivasu
}

\begin{abstract}
A multipurpose dam serves multiple modalities like agriculture, hydropower, industry, daily usage. Generally dam water level and inflow are changing throughout the year. So, multipurpose dams require effective water management strategies in place for efficient utilization of water. Discrepancy in water management may lead to significant socio-economic losses and may have effect on agriculture patterns in surrounding areas. Inflow is one of the dynamic driving factors in water management. So accurate inflow forecasting is necessary for effective water management. For inflow forecasting various methods are used by researchers. Among them Auto Regressive Integrated Moving Average (ARIMA) and Artificial Neural Network (ANN) techniques are most popular. Both of these techniques have shown significant contribution in various domains in regards to forecasting. But they have a common drawback in handling non-stationary inflow patterns. To address this drawback, in this work neural Reservoir Computing technique is used. In this work, Context reverberation network, also known as reservoir computing approach, is applied for inflow forecasting. It comprises of a dynamic neural reservoir. As the nature of a neural reservoir is dynamic, it can easily model complex non-stationary patterns along with stationary ones. Proposed model is applied on daily inflow data of Srisailam Dam which is a multi-purpose dam. Here ARIMA and ANN models are compared with Reservoir Computing model. On various evaluation parameters Reservoir computing is proved better than ARIMA and ANN.
\end{abstract}

Keywords; Water Management, Reservoir Computing, ARIMA and ANN.

\section{I.INTRODUCTION}

Water from a dams or embankments has various usages for mankind [1]. Proximity areas can get rich in water resource for agriculture, hydropower, industry, and daily usages. Forecasting inflow data can help better plan and manage the available water. In case there is a possibility of high inflow then such extra water can be redirected in canals for agriculture and industry usage. On the other hand if there is limited water supply and even inflow is not very significant then water can be managed efficiently for drinking purposes of populous. A particular dam should effectively manage various needs of surrounding area and also should take care of need of the sub-basin areas.. Also, if the dam is at high altitude then it can be very effectively be used for hydropower generation for supporting electricity needs of nearby area. Inflow forecasting can greatly stabilize water management procedures.

Revised Manuscript Received on December 30, 2019.

* Correspondence Author

B. Pradeepakumari, Dept. of Civil Engg., Acharya Nagarjuna University, Guntur (Andhra Pradesh) India.

Kota Srinivasu,,Dept. of Civil Engg., RVR\&JC College of Engnn., Guntur (Andhra Pradesh) India.

(C) The Authors. Published by Blue Eyes Intelligence Engineering and Sciences Publication (BEIESP). This is an open access article under the CC BY-NC-ND license (http://creativecommons.org/licenses/by-nc-nd/4.0/)
Also, it can insure that available water supply is used effectively. In work [1] various methods for water management at the same time effect of embankment on biological aspects is studied. A practical approach for water management is presented with case study in work [2]. On the other hand $[3,4]$ has highlighted importance of inflow predictions for water management. Classical rainfall and runoff models exist, such as empirical, conceptual, physically, and data-driven [5,6]. Data-driven models in different fields of water resources with $[7,8,9]$ can be modeled effectively for water management. At the same time, researchers have realized complex nature of relationship between rainfall and runoff so various complex models are introduced like fuzzy logic [10], support vector regression [11], and Artificial Neural Networks (ANN) $[6,12]$. Neural networks have been widely applied as an effective method for modeling highly nonlinear phenomenon in hydrological processes [13]. Artificial Neural Networks (ANN) are good in modeling stationary patterns in inflow but non-stationary patterns cannot be well modeled by them. So, latest neural reservoir computing based model is proposed here for inflow forecasting.

Here in this work, reservoir computing paradigm of Artificial Neural networks (ANN) is used. Reservoir computing performs training efficiently with very low computational cost compared to ANNs. It is due to the fact that training is limited only to the output layer all other layers need not be trained [14]. Because a reservoir is a dynamic system its capable of modeling complex sequences. This paradigm has shown its steady performance in various domains like wind power, finance, weather, on time series forecasting problems $[15,16]$.

\section{II.SYSTEM DESCRIPTION}

With goal of harnessing hydroelectric power Srisailam Dam was constructed. It is second largest hydroelectric station in India. It is on Krishna River on Andhra and Telangana border. This dam is located close to the famous Srisailam temple. Nallamala Hills are host of this dam in between Mahabubnagar and Kurnool districts, 300 m (980 $\mathrm{ft}$ ) above sea level. It is highest located dam in India. It is $512 \mathrm{~m}$ (1,680 ft) long, 145 meters (476 ft) maximum height and has 12 radial crest gates. It has a reservoir of 616 square kilometers (238 sq m). Project has an estimated live capacity to hold $178.74 \mathrm{Tmc} \mathrm{ft}$ at its full reservoir level of 885 feet $(270 \mathrm{~m})$ mean sea level. The left bank underground power station houses 6 x 150 megawatts (200,000 hp) reversible pump turbines for pumped-storage operation and the right bank semi-underground power station houses 7 x 110 megawatts (150,000 hp) turbines. 


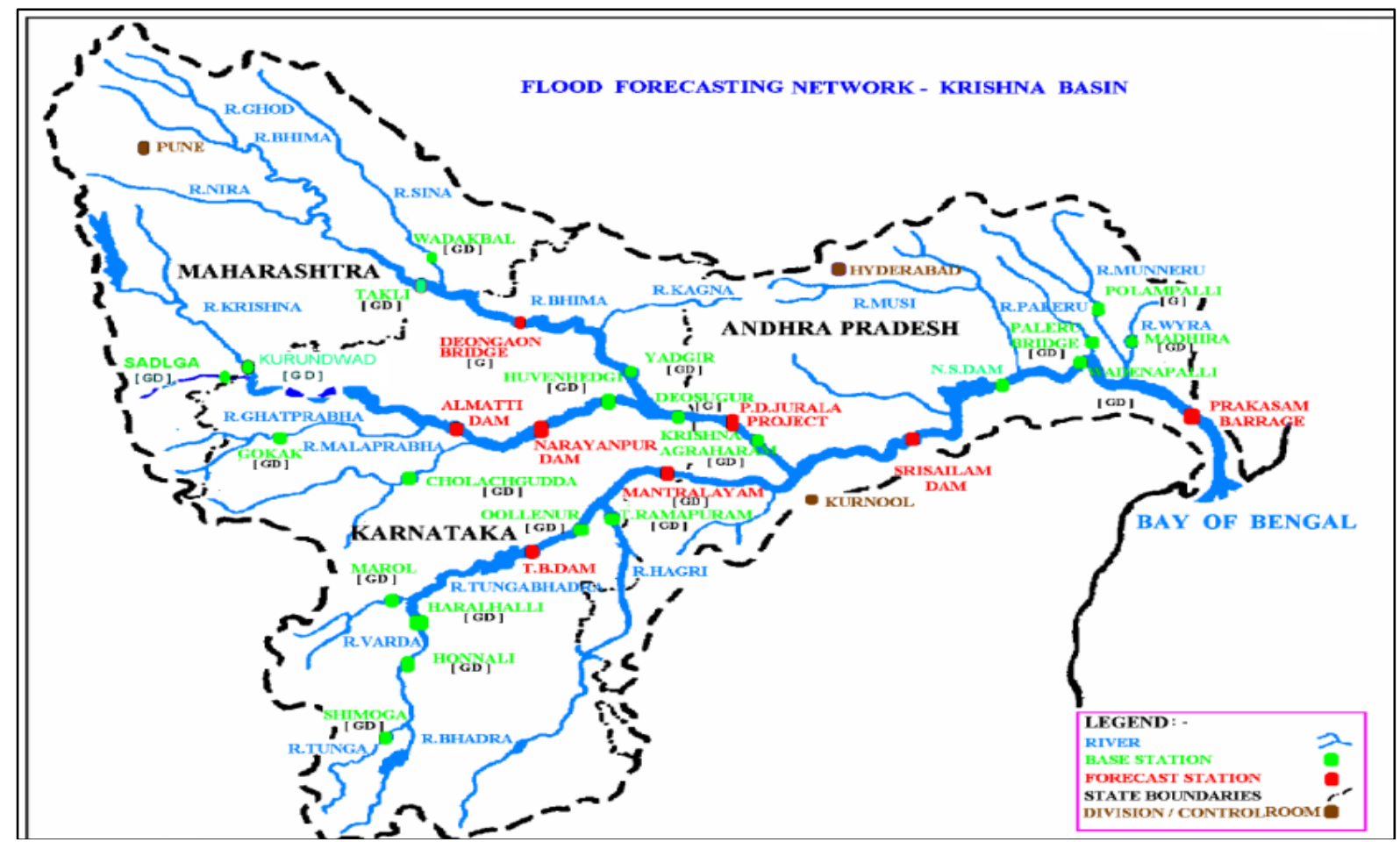

Fig 1. Krishna River Basin with Srisailam Dam

Figure 1 shows geographical location of Srisailam dam in Krishna basin. It can be clearly seen here that there are two major inflow tributaries to this dam, one from P.D. Jurala project and another from Mantralayam. In total there are eight sub basins related to this dam. Major sub basins are Upper Krishna, Middle Krishna, Ghataprabha, Malaprabha, Upper Bhima, Lower Bhima, Tungabhadra and Vedavati and part catchment of Lower Krishna sub-basin [17]

\section{Dataset}

Inflow data for 15 years starting from 2003 to 2017 is collected for Srisailam dam. Sample inflow data is shown in table 1. Descriptive statistics of this data is shown in table 2. Maximum inflow received by the dam over these years is as high as 2.2 million cum/sec. High value of standard deviation indiacates this inflow is very fluctuating at this dam.

Table 1. Sample collected inflow data from Srisailam Dam

\begin{tabular}{llllll}
\hline Date & Inflow & Date & Inflow & Date & Inflow \\
\hline $\mathbf{0 1 - 0 8 - 2 0 0 5}$ & 549713 & $\mathbf{1 1 - 0 8 - 2 0 0 5}$ & 525820 & $\mathbf{2 1 - 0 8 - 2 0 0 5}$ & 301356 \\
$\mathbf{0 2 - 0 8 - 2 0 0 5}$ & 525521 & $\mathbf{1 2 - 0 8 - 2 0 0 5}$ & 513360 & $\mathbf{2 2 - 0 8 - 2 0 0 5}$ & 322468 \\
$\mathbf{0 3 - 0 8 - 2 0 0 5}$ & 648888 & $\mathbf{1 3 - 0 8 - 2 0 0 5}$ & 154400 & $\mathbf{2 3 - 0 8 - 2 0 0 5}$ & 162515 \\
$\mathbf{0 4 - 0 8 - 2 0 0 5}$ & 680526 & $\mathbf{1 4 - 0 8 - 2 0 0 5}$ & 1123610 & $\mathbf{2 4 - 0 8 - 2 0 0 5}$ & 145492 \\
$\mathbf{0 5 - 0 8 - 2 0 0 5}$ & 758604 & $\mathbf{1 5 - 0 8 - 2 0 0 5}$ & 116560 & $\mathbf{2 5 - 0 8 - 2 0 0 5}$ & 152379 \\
$\mathbf{0 6 - 0 8 - 2 0 0 5}$ & 724180 & $\mathbf{1 6 - 0 8 - 2 0 0 5}$ & 120772 & $\mathbf{2 6 - 0 8 - 2 0 0 5}$ & 116910 \\
$\mathbf{0 7 - 0 8 - 2 0 0 5}$ & 725231 & $\mathbf{1 7 - 0 8 - 2 0 0 5}$ & 128305 & $\mathbf{2 7 - 0 8 - 2 0 0 5}$ & 98975 \\
$\mathbf{0 8 - 0 8 - 2 0 0 5}$ & 741194 & $\mathbf{1 8 - 0 8 - 2 0 0 5}$ & 229782 & $\mathbf{2 8 - 0 8 - 2 0 0 5}$ & 32532 \\
\hline $\mathbf{0 9 - 0 8 - 2 0 0 5}$ & 646950 & $\mathbf{1 9 - 0 8 - 2 0 0 5}$ & 364640 & $\mathbf{2 9 - 0 8 - 2 0 0 5}$ & 56544 \\
\hline $\mathbf{1 0 - 0 8 - 2 0 0 5}$ & $\mathbf{5 6 3 7 9 2}$ & $\mathbf{2 0 - 0 8 - 2 0 0 5}$ & $\mathbf{3 1 8 4 7 7}$ & $\mathbf{3 0 - 0 8 - 2 0 0 5}$ & $\mathbf{3 8 5 6 3}$ \\
\hline
\end{tabular}

Table 2: Descriptive statistics of Inflow data from year 2003 to 2017

\begin{tabular}{|c|c|}
\hline & Srisailam Dam \\
\hline Mean & 25836.11 \\
\hline Mode & 0 \\
\hline Median & 583 \\
\hline Standard Deviation & 84635.03 \\
\hline Minimum & 0 \\
\hline Maximum & 2200000 \\
\hline
\end{tabular}


Figure 2 and 3 depict detailed analysis of inflow data from year 2003 to 2017. Year 2005, 2006 and 2007 show major peaks in august. Also there is another peak at November in year 2009. Figure 3a shows very high average inflow for years when there were floods in Andhra Pradesh. In monthly average analysis as shown in figure 3b clearly depicts very high inflows in August, September and October. Figure 4 shows (a) ACF and (b) PACF analysis of daily inflow data.

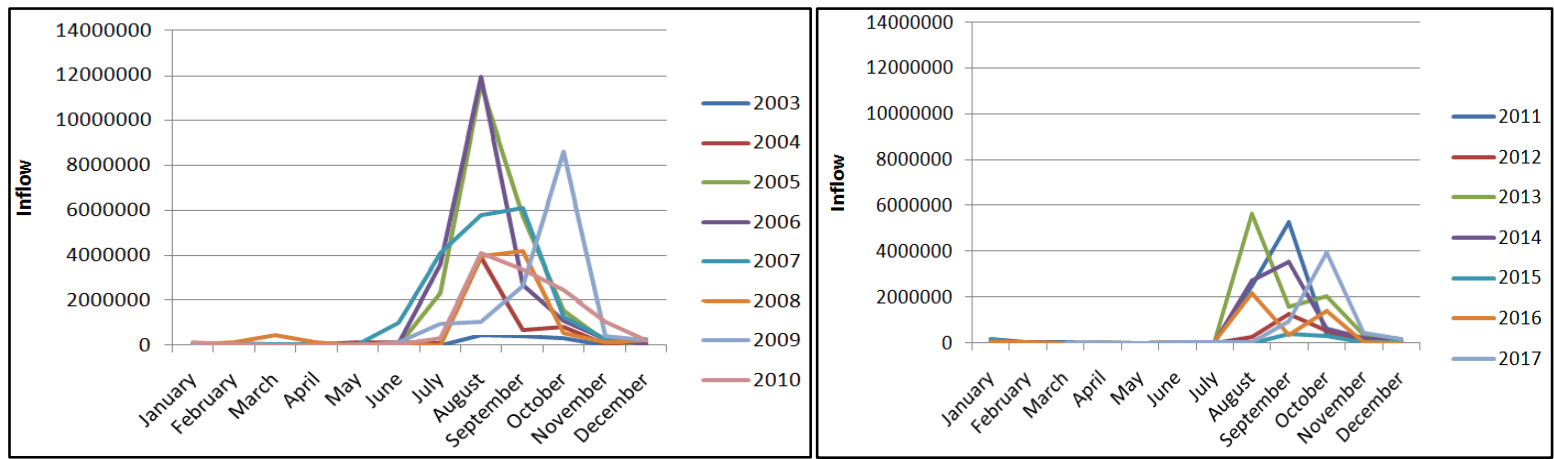

Fig 2. Inflow pattern per year in every month from a) 2003 - 2010 b) 2011 to 2017

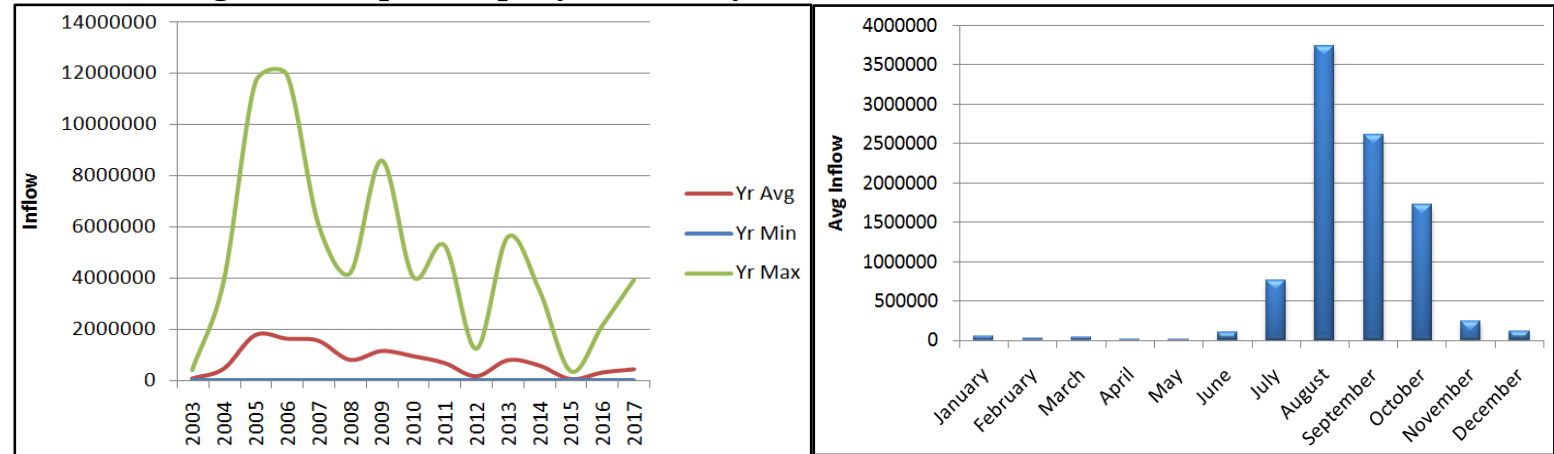

Fig 3. Average inflow a) per year b) per month

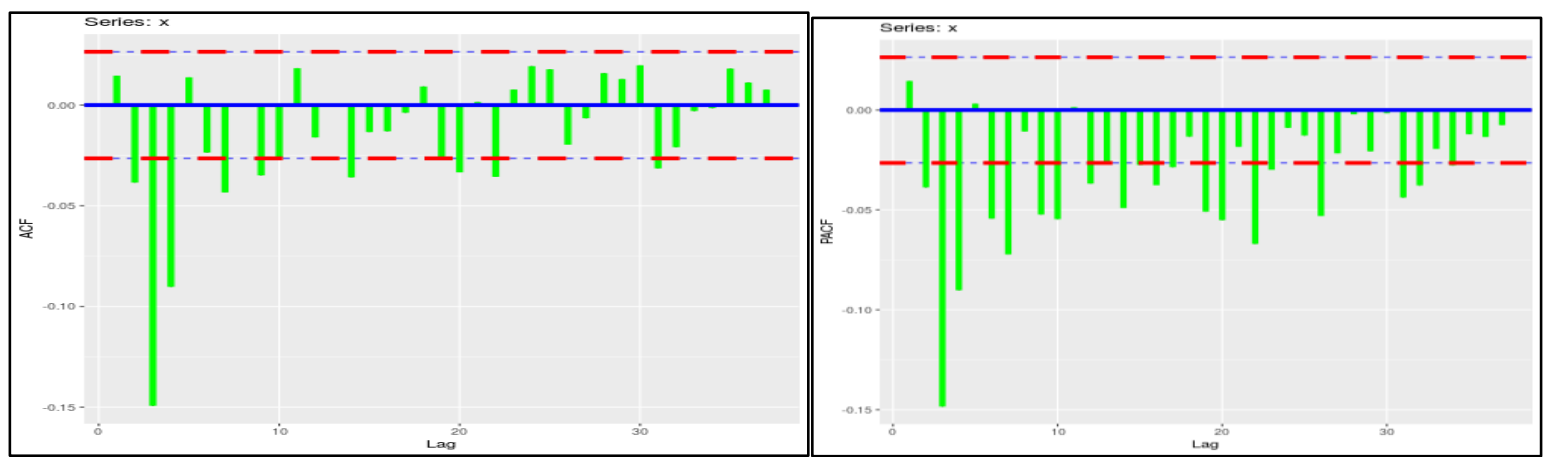

Fig. 4. ACF (a) and PACF (b) analysis of Daily inflow

\section{III.INFLOW PREDICTION METHODS}

\section{Auto Regression Integration and Moving Average (ARIMA)}

This is one of the most powerful statistical models used in forecasting. It comprises of three parts, Auto Regression (AR), Moving Average (MA) and Integration (I). Auto Regression component relates variable to itself. Here ' $p$ ' previous values of the variable are related to its current value. Another part is moving average which relates average of moving window samples with current sample. Here window size is assumes to be ' $q$ '. Central part, Integration, works by differencing provided series to itself. Degree of differencing is represented by ' $d$ ' value. Such differencing helps in better pattern modeling. So, together all these three parts can handle even very complex time series models. So, ARIMA model can be expressed in terms of ' $x$ ', ' $p$ ', ' $d$ ' and ' $q$ ' factors. Here ' $x$ ' is input to the model.

$$
\operatorname{ARIMA}(x, p, d, q)=v_{1} x_{1}+v_{2} x_{2}+v_{3} x_{3}+\ldots+v_{p} x_{p}-
$$

\section{Artificial Neural Network (ANN)}

In recent times Artificial Neural Network (ANN) based models are flooding various application domains. In field of forecasting also, they have achieved enormous results [18]. Here, multiple layers of neurons do process input, extract features with various weights, and finally leading to output. These networks can be modeled for numeric forecast or categorical forecast as well. In application field of non stationary time series forecasting, normal ANN architectures are not efficient. Normal ANN uses back propagation [19]. Training the ANN weight updating takes place at every sample in every iteration or epoch. 
Multiple such iterations or epochs are carried out to finally reach an optimal weight matrix. Eq 2 describes the back propagation updating rule.

$$
\mathrm{W}_{\mathrm{i}+1}=\mathrm{W}_{\mathrm{i}}-\alpha * \mathrm{e} \quad-\mathrm{eq}(2)
$$

Where $\mathrm{W}$ is weight matrix, $\alpha$ is learning rate and $\mathrm{e}$ $=f\left(\left\|\mathrm{O}_{\text {actual }}-\mathrm{O}_{\text {predicted }}\right\|\right)$

\section{Proposed Context reverberation network (Reservoir Computing) Model}

Context reverberation network, also known as Reservoir computing, is latest paradigm in Artificial Neural Networks (ANN). Here there are three major parts input layer, output layer and a neural reservoir. Input and output layers are as per the traditional neural networks [20]. Input layer configuration is dependent on actual input. Also, output layer will have a fix single neuron as output will be a regression value. Figure 5 shows a sample reservoir computing model.

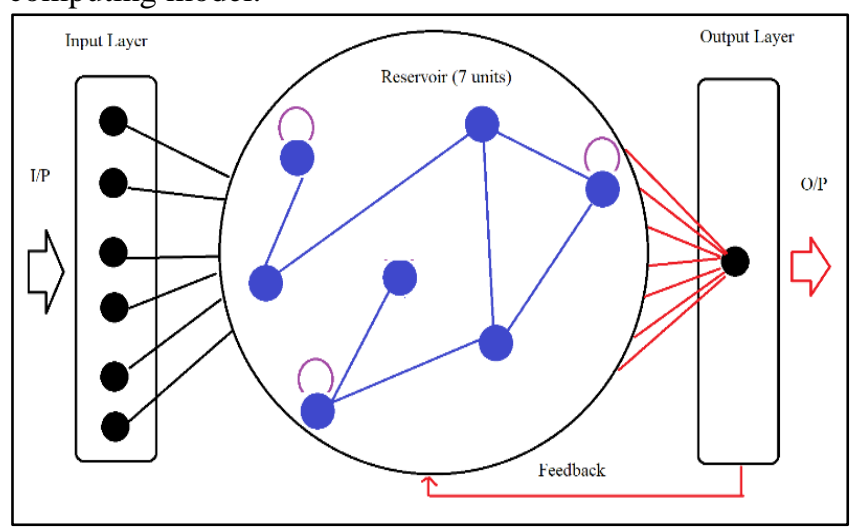

Fig 5. Proposed Context reverberation network (Reservoir Computing) Model

A reservoir is named after its unique structure of interconnected neurons. Neurons are sparsely connected to each other in a hyper spherical fashion and there can be self loops as well. Each reservoir has an internal state consisting of weights of each neuron in the reservoir. Reservoir has certain characteristics like sparesity, separability, and echo.

a. Reservoir Separability

This is measure for distance between the internal states generated. For given input (I) and its previous value, distance is calculated. This distance is finally averaged out. This measure is known as Mean Approximate Separability (MAS) [20].

$$
\text { MAS }=\frac{\sum_{j=0}^{n} \operatorname{dist}\left(I_{j}-I_{j-1}\right)}{n}-\mathrm{eq}(3)
$$

b. Reservoir Echo Property:

This property ensures that measure changes doesn't happen to input which may lead to gradient explosion problem. Here changes in input at every neuron of reservoir are caped to ' $\delta$ '. Value of ' $\delta$ ' is always limited between 0 to 1 [20]. Let, at any time ' $t$ ', $x t$ be input to a neuron in reservoir and yt is output generated by that neuron, then relation between input and output can be expressed by eq 4 .

$$
\left\|\mathrm{x}_{\mathrm{t}}-\mathrm{y}_{\mathrm{t}}\right\| \leq \delta \quad 0 \leq \delta \leq 1 \quad-\mathrm{eq}(4)
$$

\section{Training and Predictions of Reservoir Computing}

In reservoir computing weights of input layer $\left(\mathrm{W}_{\text {in }}\right)$, weights of reservoir $\left(\mathrm{W}_{\text {res }}\right)$ and feedback weights $\left(\mathrm{W}_{\mathrm{fb}}\right)$ are fixed [21]. Training happens only on weights of output layer $\left(\mathrm{W}_{\text {out }}\right)$. For this purpose matrix I containing all input training records and $\mathrm{Y}$ matrix containing all predictions for corresponding records is used.

Reservoir's state is determined by current input, previous state and previous output. Lets assume $\mathrm{x}(\mathrm{t})$ denotes state for $\mathrm{t}^{\text {th }}$ input $\mathrm{I}(\mathrm{t})$. Similarly, $\mathrm{O}(\mathrm{t})$ is output.

$$
\mathrm{x}(\mathrm{t})=\mathrm{f}(\mathrm{I}(\mathrm{t}), \mathrm{x}(\mathrm{t}-1), \mathrm{O}(\mathrm{t}-1)) \quad-\mathrm{eq}(5)
$$

When all samples one by one are given to the reservoir, then it will generate state matrix $\mathrm{X}$. State matrix contains states or output of reservoir for each training input.

$$
\mathrm{W}_{\text {out }}=\mathrm{X}^{-1} * \mathrm{Y} \quad-\mathrm{eq}(6)
$$

In testing phase, calculated $\mathrm{W}_{\text {out }}$ and all other existing weights are used. Now prediction $\mathrm{P}(\mathrm{t})$ for input $\mathrm{I}(\mathrm{t})$ is done based on input, state of the reservoir $\mathrm{x}(\mathrm{t})$ and previous output or prediction $\mathrm{P}(\mathrm{t}-1)$.

$$
P(t)=f(I(t), x(t), P(t-1)) \quad-e q(7)
$$

\section{Performance Evaluation Measures}

Evaluation of forecasting techniques is significantly different than other decision support systems or prediction systems. Here error of a model can be evaluated on four important parameters namely Mean Absolute Error (MAE), Mean Squared Error (MSE), Root Mean Squared Error (RMSE) and Mean Absolute Percentage Error (MAPE). All these values represent various aspects of error. So, all four of them are used for evaluation purpose. Here in following equations Inpred is predicted value of inflow whereas Inactual is actual value of inflow observed in dam. Also, ' $n$ ' is number of total predicted samples.

$$
\begin{array}{r}
\text { MAE }=\frac{\sum_{i=0}^{n}\left|I n_{\text {pred }}-I n_{\text {actual }}\right|}{n} \ldots \text { eq (8) } \\
\text { MSE }=\frac{\sum_{i=0}^{n}\left(I n_{\text {pred }}-I n_{\text {actual }}\right)^{2}}{n} \ldots \text { eq (9) } \\
\text { RMSE }=\sqrt{\frac{\sum_{i=0}^{n}\left(I n_{\text {pred }}-I n_{\text {actual }}\right)^{2}}{n} \ldots \text { eq }(10)} \\
\text { MAPE }=\frac{100}{n} \sum_{i=0}^{n} \frac{\left|I n_{\text {pred }}-I n_{\text {actual }}\right|}{I n_{\text {actual }}} \ldots \text { eq }(
\end{array}
$$$$
\text { ... eq }(11)
$$

\section{IV.EXPERIMENT AND RESULTS}

Experiment is carried out to compared proposed model with ARIMA and ANN models regarding to inflow forecasting. Data is taken from Government websites [21,22]. Complete data is split in training and testing parts as shown in table 3. Split is made in a continuous way and last 109 samples are reserved for testing leaving

others as a training dataset. Here, all models are first trained on training data. Then predictions are made on testing data.

Table 3. Training and Testing Dataset Details

\begin{tabular}{llllll}
\hline Sr No & $\begin{array}{l}\text { Type } \\
\text { Dataset }\end{array}$ & of & Date Range & & \\
& & & & & \\
\hline $\mathbf{1}$ & Training & $\begin{array}{l}01 / 01 / 2003 \\
\text { samples) }\end{array}$ & to & $13 / 09 / 2017$ & (5369 \\
& Dataset & & & \\
$\mathbf{2}$ & Test Dataset & $14 / 09 / 2017$ & to & $31 / 12 / 2017$ & (109 samples) \\
\hline
\end{tabular}

Results of predictions are shown in figure 6 and 7. Figure 6 shows the forecasted curve of each model with actual curve. First ARIMA curve can be clearly seen to be a general prediction. 
It has captured the lowering pattern in inflow but has missed details of peaks and valleys. On the other has ANN curve seems close to the actual predictions. But with careful observation it can be seen that ANN curve follows actual pattern. Means ANN prediction is completely dependent on actual pattern and so overfitting the dataset. It has failed to model the pattern dynamically. Finally Reservoir Computing (RC) model has shown a desirable performance. It could capture few peaks and descents. Overall it is better than both ARIMA and ANN models.

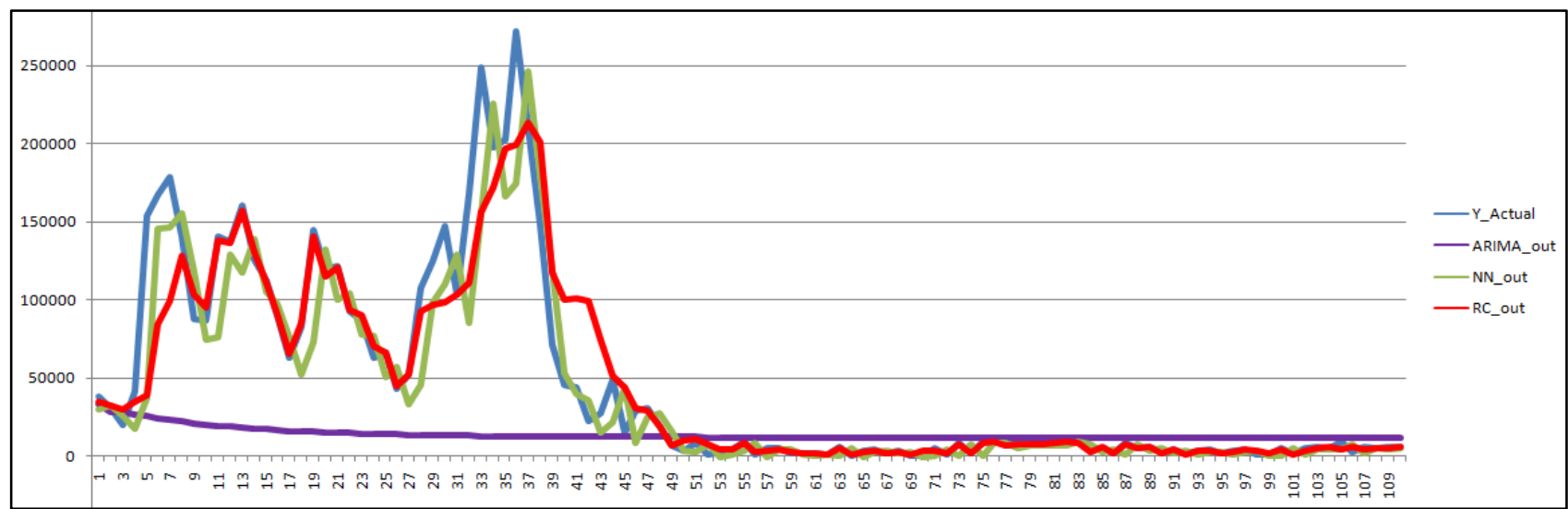

Fig 6. Comparison of ARIMA, ANN and RC for inflow forecasting

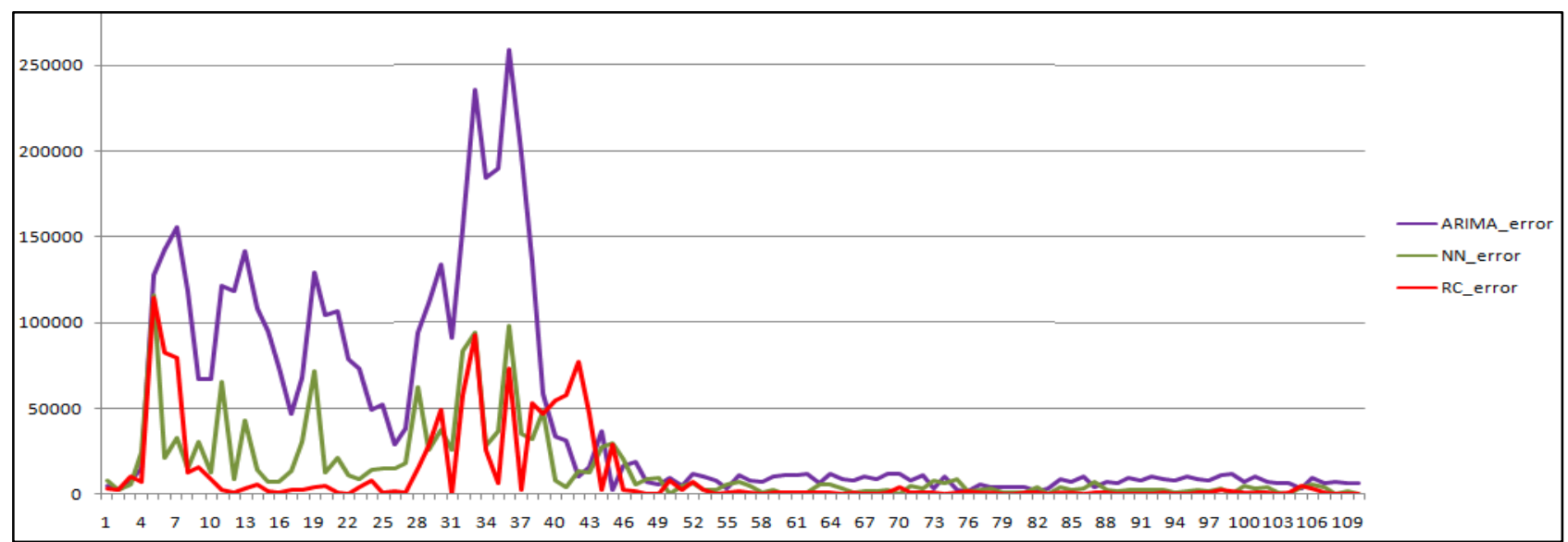

Fig 7. Absolute Error comparison for ARIMA, ANN and RC

Figure 7 makes distinction between three models very clear. Here, absolute error for each model on each sample is compared. ARIMA tops he table with highest miss values. ANN and Reservoir computing patterns are comparable. So, here it is clear that reservoir computing predictions have outperformed ANN predictions. Additionally table 4 clearly highlights average statistics of errors. In MAE, MSE, RMSE and MAPE reservoir computing has better performance than others.

Table 4. Statistical comparison for inflow predictions

\begin{tabular}{|l|l|l|l|}
\hline & ARIMA & ANN & RC \\
\hline MAE (10^3) & 5.83 & 1.92 & $\mathbf{1 . 7 6}$ \\
\hline MSE (10^6) & 41.6 & 9.63 & $\mathbf{6 . 3 2}$ \\
\hline RMSE (10^3) & 6.45 & 3.1 & $\mathbf{2 . 1 5}$ \\
\hline MAPE (10^2) & 11.69 & 2.6 & $\mathbf{3 . 0 1}$ \\
\hline
\end{tabular}

\section{V.CONCLUSION}

For a multi-purpose dam water management is a problem of significant importance. Success of water management lies heavily on accurate prediction of inflow values. So, inflow forecasting problem is focused here. Proposed Context reverberation network (reservoir computing) model is applied for inflow forecasting. Legendary ARIMA and ANN models are used here for comparison.
Dataset used here is inflow data of fifteen years (2003-2017) for Srisailam dam. Models are trained and tested on separate parts of the data. Models are compared based on Mean Absolute Error (MAE), Mean Squared Error (MSE), Root Mean Squared Error (RMSE) and Mean Absolute Percentage Error (MAPE). Results prove that neural reservoir computing model has surpassed ARIMA and ANN in all these parameters.

Results show potential of neural reservoir computing or Context reverberation network, in forecasting task. So, this model can be further applied on various civil domains like predictive maintenance of bridge, and soil moisture level prediction.

\section{REFERENCES}

1. Chapman, D. V., \& World Health Organization. (1996). Water quality assessments: a guide to the use of biota, sediments and water in environmental monitoring.

2. Whittington, D., \& Guariso, G. (1983). Water management models in practice: a case study of the Aswan High Dam. Elsevier Scientific Publishing Company.

3. Chiew, F. H. S., Zhou, S. L., \& McMahon, T. A. (2003). Use of seasonal streamflow forecasts in water resources management. Journal of Hydrology, 270(1-2), 135-144.

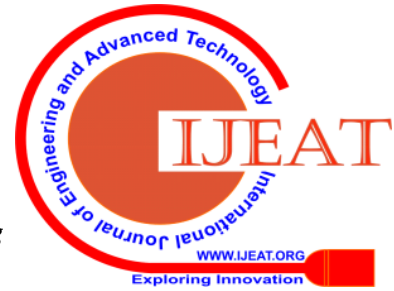


4. Mackay, C., Nachiappan, N., \& Nandakumar, N. (2015). Decision support systems and environmental water management in the Murrumbidgee valley. In 36th Hydrology and Water Resources Symposium: The art and science of water (p. 1139). Engineers Australia.

5. Verma AK, Jha MK, Mahana RK (2010) Evaluation of HEC-HMS and WEPP for simulating watershed runoff using remote sensing and geographical information system. Paddy WaterEnviron 8(2):131-144

6. Adamowski JF (2008) Peak daily water demand forecast modelling using artificial neural networks. Water ResourPlann Manage 134(2):119-128

7. Mukerji A, Chatterjee C, Raghuwanshi NS (2009) Flood forecasting using ANN, neuro-fuzzy, andneuro-GA models. J HydrolEng 14(6):647-652

8. Tiwari MK, Chatterjee C (2010) Development of an accurate and reliable hourly flood forecastingmodel using wavelet-bootstrapANN hybrid approach. J Hydrol 394:458-470

9. Tiwari MK, Song KY, Chatterjee C, Gupta MM (2013) Improving reliability of river flow forecasting using neural networks, wavelets and self-organizing maps. J Hydroinf 15(2):486-502

10. Kant A, Suman PK, Giri BK, Tiwari MK, Chatterjee C, Nayak PC, Kumar S (2013) Comparisonof multi-objective evolutionary neural network, adaptive neuro-fuzzy inference system andbootstrap-based neural network for flood forecasting. Neural ComputAppl 23(1):231-246

11. Herrera M, Torgo L, Izquierdo J, Perez-Garcia R (2010) Predictive models for forecasting hourlyurban water demand. J Hydrol 387(12):141-150

12. Tiwari MK, Chatterjee C (2011) A new wavelet-bootstrap-ANN hybrid model for daily dischargeforecasting. J Hydroinf 13(3):500 519

13. Abrahart RJ, Anctil F, Coulibaly P, Dawson CW, Mount NJ, See LM, Shamseldin AY,

14. Coulibaly, P. (2010). Reservoir computing approach to Great Lakes water level forecasting. Journal of hydrology, 381(1-2), 76-88.

15. Wyffels, F., \& Schrauwen, B. (2010). A comparative study of reservoir computing strategies for monthly time series prediction. Neurocomputing, 73(10-12), 1958-1964.

16. Wang, J., Niu, T., Lu, H., Yang, W., \& Du, P. (2019). A Novel Framework of Reservoir Computing for Deterministic and Probabilistic Wind Power Forecasting. IEEE Transactions on Sustainable Energy.

17. National Water Development Agency of India, www.nwda.gov.in

18. Cannas B, Fanni A, See L, Sias G (2006) Data pre-processing for river flow forecasting using neural networks: wavelet transforms and data partitioning. Phy Chem Earth 31(18):1164-1171

19. Partal T (2009) Modeling evapotranspiration using discrete wavelet transform and neuralnetworks. Hydrol Process 23(25):3545-3555

20. Steil, J. J. (2004, July). Backpropagation-decorrelation: online recurrent learning with $\mathrm{O}(\mathrm{N})$ complexity. In 2004 IEEE International Joint Conference on Neural Networks (IEEE Cat. No. 04CH37541) (Vol. 2, pp. 843-848). IEEE.

21. Pathak, S. S., \& Rao, D. R. (2018). INTEGRATED FROMEWORK FOR PROGNOSIS OF CERVICAL DYSPLASIA, 13(20), 83518354

22. Water Resources Information System of India, www.indiawris.nrsc.gov.in

23. Indian Water Portal, www.indiawaterportal.org

\section{AUTHOR'S PROFILE}

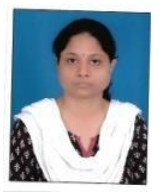

Mrs. B. Pradeepa Kumari working as Doctoral Scholr underthe department of Civil Engineering in Acharya Nagarjuna University. I am working in the area of reservoir water supply management. As a part of the fulfilment of doctoral program, i have to work for the real time data of reservoir water management.

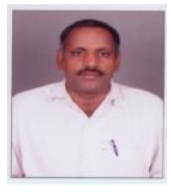

Dr. K. Srinivasu completed Ph.D in the stream of Structural Engineering - Composite Materials in 1998. have 7 years of Industrial and 35 years of academic experience. I have guided 20 Mater's projects and have 12 doctoral scholars who are working in the area of structural engineering and composite materials. 